\title{
EDITORIAL
}

\section{A Promoção da Saúde em contextos acadêmicos}

Com o propósito de oferecer aos leitores uma visão abrangente em relação à Promoção da Saúde, o volume 6 número 3 da Revista Família, Ciclos de Vida e Saúde no Contexto Social - REFACS apresenta um grupo de artigos de autores que estudam a temática, baseados em diferentes concepções e metodologias. Portanto, esta edição é fruto de algumas das produções acadêmicas do Curso de Mestrado Profissional em Promoção da Saúde do Centro Universitário Adventista de São Paulo (UNASP).

Buscando suprir o déficit do mercado de trabalho, que carece de profissionais com competências e habilidades necessárias ao trabalho interdisciplinar, o Mestrado Profissional em Promoção da Saúde procura fazer com que suas pesquisas sejam aplicadas ao cotidiano de trabalho a partir de metodologias cientificas.

Para estudar as questões pertinentes ao estilo e qualidade de vida na promoção da saúde, o curso teve suas atividades iniciadas em março de 2013. Partindo de uma visão abrangente de saúde que integre as diversas dimensões da complexidade humana, esta área de concentração constitui-se em um campo de conhecimentos e práticas que aborda os múltiplos aspectos, estratégias e intervenções relacionados com o processo de capacitação de indivíduos e de populações para a melhoria e controle sobre os determinantes da saúde e a busca da qualidade de vida.

O curso, que tem como linha de pesquisa a Qualidade e Estilo de Vida na Promoção da Saúde, almeja abordar o campo interdisciplinar de conhecimento com investigações de temas tais como: política e avaliação em promoção da saúde, promoção da saúde em atividades física e laboral, promoção da saúde no setor de alimentação e nutrição, promoção da saúde em grupos populacionais específicos, promoção da saúde com atenção à saúde mental e espiritual e, educação em saúde.

Por isto, neste número especial, um pouco do que têm sido estudado pelo grupo é apresentado na REFACS que pelo seu escopo tem relação direta com a questão e, certamente é alvo de produções que visem este importante tema.

Esperamos que esse leque temático possa trazer, além das contribuições científicas, um agradável momento de reflexão.

Boa Leitura!

Fábio Marcon Alfieri

Fisioterapeuta. Especialista em Atividade Física e Qualidade de Vida. Mestre em Fisioterapia. Doutor e Pós Doutor em Ciências Médicas. Coordenador do Mestrado Profissional em Promoção da Saúde da UNASP. 